\title{
CONTEXTO DE LA SALUD Y SEGURIDAD EN EL TRABAJO: POLÍTICA DE TUTELA EN MATERIA LABORAL. ¿CÓMO INTERVIENE EL ESTADO?
}

\author{
Context of health and safety at the workplace: protection \\ policy in labor matters. How does the State intervene?
}

Paul Yance Zamudio*

Universidad Continental

\section{Resumen}

Con base en un estudio de premisas generales y particulares, en el presente trabajo se analiza la intervención del Estado en el diseño de la política sobre seguridad y salud en el trabajo, así como en el trabajo de fiscalización del cumplimiento del marco normativo.

Palabras clave: Seguridad en el trabajo; salud en el trabajo; seguro complementario de trabajo de riesgo.

\section{Abstract}

Based on a study of general and particular premises, in the present work it is analyzed the State intervention on the design of policy on health and safety at work, as well as in the audit work of the normative framework compliance.

Keywords: Safety at work; health at work; supplemental insurance of risk work.

\footnotetext{
* Estudiante de la Facultad de Derecho en la Universidad Continental.
} 


\section{CONSIDERACIONES GENERALES AL TEMA LABORAL}

Antes de iniciar con el desarrollo del artículo es necesario precisar que el espíritu del capitalismo, tal como señala Weber, si bien descansa sobre la base de expectativas de una ganancia, éste se guía por términos éticos, protegiendose así al trabajador y al empresario consciente.

Como se observa el tema es de vital importancia no solamente económica y social, sino integral para el desarrollo humano, donde la seguridad y salud en el trabajo son aspectos que atañen a todos los actores del mercado en esta nueva era de la información y el conocimiento.

La globalización, alcanzada a partir de los desarrollos tecnológicos y económicos logrados a mediados del siglo XX y cuyo aporte nos sigue hasta la actualidad, posibilita así el ingreso de empresas extranjeras al territorio nacional, generándose en el país una dinámica de desarrollo y la necesidad de construir un país acorde a este fenómeno mundial que albergue de forma amigable a las inversiones internacionales y nacionales que, en condiciones éticas, favorece tanto al trabajador como al empresario, y evita constituir escenarios de permanente conflicto.

A partir del fenómeno de la globalización, es que ingresan al escenario diversos conceptos adicionales. De Trazegnies menciona que "[l]a industrialización, las innovaciones tecnológicas, el incremento de las velocidades y de los poderes para hacer cosas, originaron una verdadera inflación de riesgos en el mundo contemporáneo»; y sí el incremento exponencial de los riesgos a partir de los desarrollos tecnológicos parece ser una constante inevitable de tal fenómeno, y para el desarrollo del presente artículo cobran mayor importancia.

Se infiere entonces que la infraestructura institucional del país a partir de la globalización necesita ser reconstruida, mejorada, renovada y ampliada, pues es una consecuencia lógica y necesaria del desarrollo económico que genera el suceso «globalización». En razón a ello las empresas contratarán personal para materializar esos objetivos, configurándose así un escenario donde interactúan tanto el empresario como el trabajador, ambos asumiendo un riesgo necesario por las actividades económicas que deben realizar, riesgo que, según De Trazegnies, tiene que ser trasladado a quien esté en mejores condiciones de asumir los costos, agregamos, ante un eventual siniestro.

El tema central planteado es la conformación de un sistema para proteger al trabajador, pero también para educar al empresario, y lograr una acción productiva y de servicios con el objetivo de satisfacer la demanda 
de los clientes y usuarios de la sociedad, entre ellos el mismo Estado. Este contexto ideal se alcanza aparentemente con el sistema de seguros; es decir, asegurando al trabajador por la actividad riesgosa realizada, hecho resultante del imperativo legal de nuestro ordenamiento hacia el empleador, y cuyo sustento encuentra asidero a nivel nacional en la Constitución Política del Perú que en su artículo 22 establece "[e]l trabajo es un deber y un derecho. Es base del bienestar social y un medio de realización de la persona». Asimismo, internacionalmente, con la Carta Universal de Derechos Humanos a la cual debemos acudir citando los artículos 3 y 23 de los cuales se puede colegir lo siguiente: «en materia laboral se busca tutelar y promover condiciones satisfactorias de trabajo ante la labor riesgosa que debe cumplir una persona al momento de desempeñar su trabajo, agregamos, en una empresa que califica como una de actividad riesgosa».

Ahora, siguiendo con la idea, la consecuencia lógica de los riesgos asumidos por el empleador a partir del imperativo legal ya mencionado, se configura un minisistema donde se interrelacionan el empresario, el trabajador y la empresa prestadora de seguros. El empleador será el encargado de asumir el costo de pagar la prima del seguro, de la cual hablaremos más adelante, y, a su vez, el trabajador asumirá que la empresa contratará ese seguro; y si ésta no lo hace, tiene el fuero ordinario para accionar contra la empresa pidiendo los gastos en los cuales incurra a efectos de reestablecer en la mayor medida posible su salud.

Por último, la aseguradora (tercera parte del sistema) buscará evitar cubrir la totalidad del siniestro intentando atribuir el accidente de trabajo al propio empleado, siendo ese su giro económico; esto es, brindar servicios de seguro, pero esperar que el beneficiario nunca lo necesite porque si sucede la empresa de seguros atribuirá el siniestro al empleado y evitar cumplir con su obligación. Como se observa el tema es complejo y multidimensional.

\section{EL ESTADO DE BIENESTAR. UNA APROXIMACIÓN A LA SEGURIDAD LABORAL}

A partir de la propuesta del Estado de Bienestar, las naciones, a nivel mundial, adoptan medidas relacionadas con la salud y la seguridad del trabajador, trasladan al Estado la responsabilidad de garantizar a sus ciudadanos un mínimo de bienestar social'.

1 KESALJA, Baldo y César OCHOA. Derecho constitucional económico. Lima: Fondo PUCP, 2009; pp. 225-228. 
Así, en Alemania con Bismarck y su economía social, en Estados Unidos de América con Roosevelt y su New Deal, en Inglaterra con William Beveridge y su informe sobre la seguridad social y servicios sociales, se institucionaliza en diferentes fechas y países en el siglo XX el "Estado de Bienestar» ${ }^{2}$; consolidándose, poco a poco, políticas para favorecer a la mayoría de los ciudadanos. Un resultado de ese fenómeno es la seguridad social, cuya amplitud engloba muchas materias, entre ellas la seguridad en el trabajo. En el Perú esta corriente tuvo un largo proceso de maduración; los gobiernos, de manera paulatina, fueron implantando medidas sobre prestaciones sociales, pero no con el objetivo de mejorar la calidad de vida de los ciudadanos, sino que esto fue el resultado de la presión de grupos sociales vulnerables organizados, como los sindicatos de trabajadores, que conquistaron derechos, logrando así, mejorar el carácter tuitivo del Estado.

En casi todos los estados naciones, donde se ponen en práctica medidas de protección social, los derechos sociales sobre salud y educación, adquieren preponderancia y las legislaciones regulan en su normativa accidentes de trabajo, enfermedades, vejez, desempleo y educación, tal como se testimonia con los derechos laborales.

Empero, hoy en día, sobre todo en países emergentes, el estado de bienestar da señales de crisis en todas las formas de protección al trabajador; y en el país los cambios se dan con el llamado estado mínimo, como se refleja en la dación de normas como el Decreto Supremo 003-98-SA, que regula el Seguro Complementario de Trabajo de Riesgo en base a mínimas actuaciones que deben realizar tanto la empresa contratante del seguro como la empresa de seguros. Así mismo, en el campo laboral, la política de flexibilidad agudiza la crisis de las relaciones laborales porque los partícipes directos e indirectos de la relación laboral no actúan ni siquiera bajo el alcance de los mínimos impuestos por normas legales.

\section{EL MERCADO LABORAL}

Un mercado laboral autosuficiente, aplicando la tesis de Ronald Coase ${ }^{3}$, explicaría y fundamentaría a cabalidad el supuesto de la mínima intervención de Estado, contexto favorable para la dinámica de mercado, pero antes de abordar este enunciado primero tenemos que graficar el mercado laboral, por ejemplo:

2 URIBE, Consuelo. Un modelo para armar. Teorías y conceptos de desarrollo. Lima: Fondo PUCP, 2008; pp. 59-61.

3 COASE, Ronald. El problema del costo social. Disponible en http://www.hacer.org/pdf/coase2.pdf. 
A es una municipalidad que desea construir un nuevo local, para ello, a través de una licitación pública de obras, contrata a $\mathbf{B}$ para que realice la edificación, quien a su vez tiene en su plana a personas especializadas en diversas ramas del ámbito de construcción, como arquitectos e ingenieros. La empresa $\mathbf{B}$ contrata a $\mathbf{C}$ para realizar labores no especializadas en la obra y $\mathbf{C}$ subcontrata a peones y oficiales para el traslado y vigilancia de los materiales.

Hagamos un paréntesis en este punto para precisar que, la cantidad de actores en este caso ha aumentado, ya no solo está la empresa que realiza la obra sino también entra a tallar una municipalidad y una empresa subcontratista, así como los trabajadores que están divididos entre arquitectos e ingenieros contratados directamente por la empresa B y por otro lado estarán los peones y oficiales quienes fueron contratados por la empresa $C$ para realizar labores en la empresa $B$, además aún nos falta citar aquí a la empresa prestadora de seguros, la cual trae consigo algunas interrogantes, por ejemplo: ¿Quién debe contratar y pagar la prima del Seguro Complementario de Trabajo de Riesgo, respecto de los dos tipos de trabajadores?

Antes de responder a esta interrogante, que ampliará nuestro panorama, primero terminaremos de analizar el planteamiento de Ronald Coase; esto es que si, en el caso planteado, cada una de las partes cumpliera su rol en el mercado laboral, la intervención del Estado, a través de la inspección laboral, no sería continua, ahorrándose recursos monetarios y, sobre todo, recursos humanos puesto que habrían menos inspecciones de investigación, cuyo objetivo es verificar el cumplimiento de derechos laborales, y dirigir los recursos hacia las inspecciones de orientación, cuya finalidad es pedagógica.

Para que el mercado se regule solo, deberíamos seguir el imperativo categórico de Kant y decir que si la empresa tiene a su cargo trabajadores que realizan labores para el beneficio empresarial, yo como empresa debería cuidar de esos trabajadores, cumpliendo con las normas morales (mínimos legales) de protección al trabajador, quien al verse respaldado por la empresa responderá de manera positiva, recíproca, en el trabajo.

Por otro lado, la empresa de seguros no tiene que ser el leviatán de la relación, más bien debe ser parte coadyuvante para incentivar al empresario a asegurar al trabajador y asumir una simple política que De Trazegnies configura de la siguiente manera: Establecer primas diferenciadas según el riesgo, es lógico, no es igual el riesgo que tiene un peón que lleva piedras dentro de la reciente edificación, al del administrador que se encuentra en la oficina cerca de la construcción; además tiene que desarrollar una polí- 
tica de disminución de primas a pagar si no hay ni un accidente durante la construcción ${ }^{4}, y$, agregamos, este beneficio debería ser acumulativo, esto es para los sucesivos proyectos u obras, aquella política entonces desde la perspectiva del empleador podría significar un cambio importante, pues el empresario vería estos incentivos como una suerte de oferta de la cual de una u otra forma saldrá beneficiado.

Respecto a la pregunta la legislación nacional de acuerdo al Decreto Supremo 003-98-SA, en su artículo 5 ha establecido cuál es la empresa obligada a contratar el seguro. En ese sentido, teniendo como premisa el ejemplo antes planteado, diremos que la empresa B está obligada a contratar un seguro en beneficio de sus trabajadores (arquitectos e ingenieros); así mismo la empresa C estará obligada a contratar prima facie, el seguro como empresa subcontratista, a favor de los trabajadores contratados directamente (peones y oficiales), pero respecto a lo último será B quien deberá verificar si los trabajadores proveídos por la empresa C están asegurados; si ésta no lo hace B deberá contratar por cuenta propia el seguro, caso contrario, responderá de manera solidaria con la empresa subcontratista $C$ por las consecuencias patrimoniales que genere el siniestro respecto del trabajador y, si además lo concordamos con el reglamento de la ley general de Inspección, consideraremos esa infracción como una falta grave y recibirá una multa en caso de ser una materia insubsanable por cada trabajador afectado.

\section{INSPECCIÓN LABORAL. ESTADO DE LA CUESTIÓN}

En la interacción laboral empresario y trabajador, las normas nacionales e internacionales tutelan dos grandes grupos de derechos: por un lado, estarán los derechos sociolaborales y, por otro lado, los derechos nacidos de normas de seguridad y salud en el trabajo. Los primeros versarán sobre el pago de gratificaciones, vacaciones (llámese truncas, legales o no gozadas), Compensación por el Tiempo de Servicio, estar en planilla, entre otros; los segundos son imperativos legales sobre políticas de seguridad y salud en el trabajo, como por ejemplo planificar acciones preventivas de riesgo, formar e informar a los trabajadores sobre su actividad (sobre todo si es riesgosa), nombrar a un comité de seguridad y también de salud, entre otros.

Es necesario establecer que si en la interrelación tridimensional planteada sucede que la empresa ejecutora de la obra y la empresa prestadora

4 DE TRAZEGNIES, Fernando. Ob. cit. p. 53. 
de seguros no cumplen a cabalidad con su rol en el mercado laboral, respecto del trabajador, el Estado deberá intervenir en esta interrelación no sólo con la dación de normas sino también a través de la figura de la «inspección laboral», cuyo sustento se encuentra en normas internacionales como el Convenio 81 (1947) de la Organización Mundial del Trabajo, donde el artículo 3 nos da visos de los objetivos y finalidades principales de ese instrumento; así mismo en el ámbito nacional tenemos a la Ley N. ${ }^{\circ} 28806$, Ley General de Inspección de Trabajo, del ordenamiento jurídico siguiendo la línea del convenio, regula para el territorio pervano la Inspección Laboral. La conclusión lógica de lo mencionado es que los partícipes no cumplen de manera ética su rol, respecto a su responsabilidad social, permitiendo así la intervención continua del Estado, pero si se llegase a una interrelación en el mercado de manera eficiente se debería inferir que no es necesaria la intervención del Estado a través de esta figura jurídica actualmente contemplada, porque, como lo menciona Ronald Coase en el problema del costo social ${ }^{5}$, el mercado laboral sería autosuficiente para regular su interrelación, cumpliéndose los mínimos legales establecidos.

\section{INTERVENCIÓN REACTIVA DEL ESTADO COMO CONSE- CUENCIA DE LA RELACIÓN LABORAL CONFLICTIVA}

Es necesario en este acápite hacer una mención estadística para dar validez a las conclusiones a las que arribaremos más adelante, basándonos en todo lo mencionado y argumentado anteriormente.

La intención de ofrecer datos estadísticos sobre accidentes de trabajo tiene como finalidad establecer que en el Perú se realizan actividades de riesgo y que dentro de los diversos regímenes laborales que se pueden vislumbrar en el panorama de trabajo a nivel nacional, se encuentran, por ejemplo, el régimen de Construcción Civil, el régimen laboral portuario, el régimen minero, el régimen del trabajador pesquero en condiciones de dependencia, —incluso- el régimen de la microempresa y el régimen laboral del trabajador a tiempo parcial si las actividades que realizan sus trabajadores están bajo los alcances de una actividad riesgosa ${ }^{6}$ o las empresas están registradas como empresas que realizan actividades de riesgo ante el $\mathrm{Mi}$ nisterio de Trabajo.

5 COASE, Ronald. Ob. cit.

6 Campos, Sara (noviembre-2014). Regímenes Laborales Especiales 2014. Lima. Rev. Gaceta Jurídica. Edit. El Búho. 
Todos los regímenes laborales ya citados tienen en común que las empresas deben contratar a favor de sus empleados, en materia de seguridad y salud en el trabajo, un Seguro Complementario de Trabajo de Riesgo (en adelante, SCTR). Este seguro cubre las prestaciones de salud y pensiones a favor de los trabajadores que sufran una enfermedad profesional o tengan un accidente de trabajo. En el cuadro ${ }^{7}$ siguiente procederemos a analizar datos sobre los accidente de trabajo en el Perú y en la región Junín.

Cuadro. Accidentes de trabajo en el Perú y la región Junín (2012-2015)

\begin{tabular}{|c|c|c|c|c|}
\hline & \multicolumn{2}{|c|}{ Nacional } & \multicolumn{2}{c|}{ Región Junín } \\
\hline & Mortales & No mortales & Mortales & No mortales \\
\hline 2012 & 15508 & 190 & 11 & 4 \\
\hline 2013 & 18962 & 178 & 55 & 6 \\
\hline 2014 & 14750 & 128 & 30 & 1 \\
\hline $\begin{array}{c}\text { Hasta marzo } \\
\text { del 2015 }\end{array}$ & 4258 & 46 & 6 & 1 \\
\hline $\begin{array}{c}\text { Total de } \\
\text { accidentes }\end{array}$ & $\mathbf{5 3 4 7 8}$ & $\mathbf{5 4 2}$ & $\mathbf{1 0 2}$ & $\mathbf{1 2}$ \\
\hline
\end{tabular}

Elaboración propia.

Del cuadro anterior, se debe entender:

- Primero que en el 2012 los accidentes registrados en la región Junín equivalen al 0,07 \% de los accidentes a nivel nacional. Así mismo los accidentes mortales de la región Junín representan el 2,11 \% de los accidentes mortales a nivel nacional en el mismo año.

- Segundo que en el 2013 los accidentes registrados en la región Junín equivalen al 0,29 \% de los accidentes a nivel nacional. Así mismo los accidentes mortales de la región Junín representan el 3,37\% de los accidentes mortales a nivel nacional en el mismo año.

7 Ministerio de Trabajo y Promoción del Empleo. Accidentes de trabajo. Recuperado el 24 de junio de 2015 de http://www.mintra.gob.pe/mostrarContenido.php?id=730\&tip=86 
- Tercero que en el 2014 los accidentes registrados en la región Junín equivalen al 0,20 \% de los accidentes a nivel nacional. Así mismo los accidentes mortales de la región Junín representan el 0,78 \% de los accidentes mortales a nivel nacional en el mismo año.

De los datos presentados se observa que los accidentes de trabajo no tienen una línea constante, porque son hechos eventuales que no se pueden prever por el Estado, por la empresa y menos por el trabajador, es por ello que en todo el 2014 en la región Junín sólo ha existido un siniestro mortal y que a marzo del 2015 ya existía una persona fallecida por un accidente. Este contexto de incertidumbre nos trae como es lógico muchos problemas.

Un primer problema que podemos plantear a partir de los datos obtenidos del registro estadístico de siniestros laborales del Ministerio de Trabajo, es la imposibilidad de predecir, como es lógico, cuántos siniestros (accidentes de trabajo) se van a suscitar en un año determinado y menos aún cuántos siniestros habrán en alguna región del país, pero esta incertidumbre es extensiva también al empleador, configurándose así una serie de supuestos que podemos graficar a partir del ejemplo planteado en el acápite tercero. Por ello podríamos plantear primero un escenario donde la empresa $C$ no contrata el SCTR para Juan, y a su vez la empresa B no se percata de esta omisión, no obstante durante el periodo trabajado por Juan éste no sufre ningún accidente.

Un segundo escenario se puede dar si la empresa $B$ se percata de la omisión voluntaria o involuntaria de $C$, y la obliga a contratar y pagar el SCTR, porque sabe que la responsabilidad es solidaria frente a un eventual siniestro.

Un tercer escenario posible es que la empresa $C$ no contrate ni pague el SCTR y además la empresa $B$, dolosamente, no observe dicha omisión y el trabajador sufra un siniestro.

Del primer escenario podemos analizar varios elementos adicionales que ingresan a partir del incumplimiento de derechos laborales. Desde el punto de vista de Ronald Coase, el mercado laboral no se ésta autorregulando, por ello aumenta el costo del riesgo ante un posible siniestro que de por sí ya es alto; por ende, tácitamente, se solicita la intervención del Estado. Este hecho configura la intervención reactiva del Estado, que debe reaccionar para subsanar las fracturas del mercado e intervenir de manera indirecta a través de la dación de normas que establecen sanciones ante el incumplimiento de derechos, como la seguridad en el trabajo, o creando instituciones especializadas para la supervisión de derechos (SUNAFIL); 
además interviene de manera directa mediante la inspección laboral, cuya naturaleza jurídica es ser un instrumento jurídico básico para la protección de ciertos derechos.

El problema principal que genera el control del Estado no radica en la intervención en sí misma sino que ésta es obligada y no voluntaria, lo cual ameritaría un estudio sesudo y calmado de lo que va a normar, se empieza a legislar de manera inconsecuente pensando que el aumento de sanciones, como es común del Estado cuando quiere resolver un problema fáctico, es la solución.

El problema no termina ahí, se agudiza, por ejemplo, si citamos dos conceptos, ya antes mencionados, como la inspección laboral y el Seguro Complementario de Trabajo de Riesgo. La inspección laboral es una institución jurídica mínima de tutela de derechos; es decir, nace en nuestro ordenamiento jurídico como un instrumento para asegurar el cumplimiento de los derechos laborales. Por lo tanto, la Ley N. 28806 se alza como una norma que regula en base a mínimos por su condición general.

En el segundo supuesto se puede observar una conducta diligente, dirigida a la salvaguarda de los derechos laborales. Dentro de ese contexto y, sobre todo, si éste fuera constante, el Estado no debería realizar tantas actuaciones investigativas de oficio; por el contrario, debería realizar inspecciones orientadoras para mantener informados de los cambios normativos tanto al empleado como al empresario, configurándose así una verdadera política de prevención en base a la información y no en base a las sanciones.

El tercer supuesto nos pone otra vez ante un supuesto donde son las partes intervinientes del mercado laboral las que no apoyan al Estado en el cumplimiento de normas mínimas. Esto genera una reacción por parte del Estado respaldado por su función tuitiva. Además si las acciones tomadas para el primer supuesto no son suficientes, la lógica de un Estado como el nuestro para este tercer supuesto sería normar sanciones más duras e intervenir con mayores instrumentos en el mercado laboral.

Como se puede apreciar el panorama es problemático.

\section{VI.EL PROBLEMAY CONSECUENCIAS DE LA INTERVENCIÓN REACTIVA DEL ESTADO}

La ley general de inspección contiene en su estructura normativa varios componentes, los cuales hemos citado a groso modo a lo largo del presente artículo. Una de las principales figuras incorporadas en la ley General de 
Inspección de Trabajo son las formas de inspección, por ejemplo, las inspecciones investigativas y las inspecciones orientadoras; además se incorpora la figura de los inspectores que en materia de trabajo serán inspectores laborales, quienes tendrán a su cargo supervisar los dos grandes grupos de derechos laborales mencionados en la primera línea del apartado cuarto.

Una de las facultades que otorga la ley a los inspectores de trabajo, por ser representantes directos del Estado en su función tuitiva, es la capacidad de imponer multas a las empresas que violen los derechos laborales. Asimismo, el reglamento de la norma citada establece el régimen de graduación de multas ante una falta leve, grave o muy grave; al mismo tiempo indica qué infracciones son subsanables e insubsanables.

Para graficar de mejor manera lo mencionado diremos que para la ley una infracción leve es, por ejemplo, «la falta de orden y limpieza del centro de trabajo, que no implica riesgo para la integridad física y salud de los trabajadores». La infracción grave se configura cuando «no se cumple con las obligaciones relativas al Seguro Complementario de Trabajo de Riesgo (SCTR) a favor de los trabajadores, incurriendo en una infracción por cada trabajador afectado». La infracción muy grave, según la norma, se da cuando «no se implementa un sistema de gestión de seguridad y salud en el trabajo o por no tener un reglamento de seguridad y salud en el trabajo». Por último, para analizar lo concerniente a las infracciones subsanables e insubsanables, tomaremos como ejemplo los derechos sociolaborales a fin de explicar cuándo una materia es subsanable. El pago de la compensación por tiempo de servicios es un ejemplo común para graficar esto, verbigracia, al momento de realizar una actuación inspectiva el inspector de trabajo puede observar que a los primeros días de mayo del 2015 aún no se ha consignado en la cuenta del trabajador la compensación por tiempo de servicios; pero si en ese instante el empleador cumple con el depósito, estaría subsanando la omisión, como consecuencia de ello el inspector termina el proceso investigativo con un informe y no con una acta de infracción (multa).

Ahora respecto a las materias insubsanables, tenemos la excusa perfecta para justificar la mención continua del SCTR en el presente artículo; y, para analizar este seguro correctamente debemos citar el Decreto Supremo 003-98-SA8 en el cual se regulan las reglas técnicas del Seguro Complementario de Trabajo de Riesgo (SCTR), institución que fácilmente puede ser considerada como un producto lógico del Estado de Bienestar; y que,

8 Decreto Supremo 003-98-SA, Normas Técnicas del Seguro Complementario de Trabajo de Riesgo. 
sólo en un contexto democrático, este Estado, puede ser igualado, en la actualidad, a un Estado Democrático de Derecho?.

Como ya se mencionó, el SCTR es parte del grupo de derechos de seguridad y salud en el trabajo; por lo tanto, si un trabajador ha sufrido un accidente y muere, el inspector de trabajo está obligado a revisar primero el SCTR, y si el empresario no aseguró al trabajador, nos encontraremos ante una materia insubsanable, porque no se podría inscribir al trabajador en ese momento, como es lógico, al SCTR porque el trabajador ya murió. Sin embargo, el caso se complica si el inspector concurre al centro de trabajo antes de que se haya suscitado el accidente y verifica que uno o varios trabajadores no cuentan con el SCTR. Las preguntas que surgen son ¿qué sucedería en ese caso?, ¿cómo debe actuar el inspector?, ¿estamos ante una materia subsanable o insubsanable? y ¿cómo calificará este hecho el inspector?

Respecto de lo preguntado, debemos partir de la premisa que los efectos del seguro no son retroactivos, sino que surten sus efectos a partir del pago de la prima del seguro; así mismo, el problema radica también en la graduación de las multas cuando las materias no tienen criterios claros. Se configura así el tema central de discusión: ¿Cómo interviene el Estado en ciertas situaciones?

Graficar a través de ejemplos los conceptos como la inspección laboral, las materias subsanables e insubsanables y la problemática de éstas frente a la discrecionalidad que tienen los inspectores a partir de la ley general de inspección laboral y su reglamento, nos llevaría a presumir tal vez que el objetivo de las interrogantes planteadas es analizar si corresponde o no legislar un listado de materias subsanables o insubsanables, o a clarificar y a ampliar los vagos criterios en la graduación de sanciones del art. $38^{\circ}$ de la Ley General de Inspección ${ }^{10}$ para que los criterios dispersos de los inspectores al momento de calificar las infracciones conforme al SCTR sean uniformes, o tal vez a analizar si se legisló correctamente respecto al SCTR o la figura de la inspección laboral; y por último a analizar si está bien crear una institución nacional de fiscalización laboral (SUNAFIL) o si para el empresario es más barato pagar la multa por violar los derechos laborales que cumplir con los derechos, ya sean sociolaborales o derechos de seguridad y salud en el trabajo. Pero ese no es el objetivo.

9 KESALJA, Baldo y César, OCHOA. Ob. cit. p. 226.

10 Ley N. ${ }^{\circ} 28806$, Ley General de Inspección del Trabajo. 
Las interrogantes planteadas líneas arriba tienen como finalidad concientizar al empleador sobre su responsabilidad social, pero no explicándole sus derechos y deberes para con sus trabajadores porque ya los conoce, sino para hacerle entender que si no cumple con los derechos laborales fundamentales mínimos protegidos a nivel nacional e internacional ocasiona la intervención del Estado. En el caso peruano, quiérase o no, de un estado tercermundista que, ante la presión de solucionar las continuas infracciones, va a intervenir obligado por el contexto y este Estado nuestro siempre tiende a solucionar los conflictos sociales aumentando las sanciones a los infractores; por ello el empresario debe entender que cumplir las normas mínimas impuestas por el Estado le va a generar menor intervención del Estado en forma indirecta (normas y creación de instituciones-SUNAFIL) o directa (inspección investigativa laboral por servidores públicos), y que, si esa forma de intervención no es suficiente para persuadir a las partes corporativas incluidas en el mercado laboral ocasionarán, por ejemplo, la dación de leyes como la Ley N. ${ }^{\circ} 30222$, modificatoria de la Ley N. ${ }^{\circ} 29783$ que impone:

$\mathrm{Si}$, como consecuencia de la inobservancia deliberada de las normas de seguridad y salud en el trabajo, se causa la muerte del trabajador o terceros o le producen lesión grave, y el agente pudo prever este resultado, la pena privativa de libertad será no menor de cuatro ni mayor de ocho años en caso de muerte y, no menor de tres ni mayor de seis años en caso de lesión grave. Se excluye la responsabilidad penal cuando la muerte o lesiones graves son producto de la inobservancia de las normas de seguridad y salud en el trabajo por parte del trabajador...

encontrándonos así en una disputa interminable.

Por ello cobra gran relevancia hacerle entender a las partes intervinientes del mercado laboral que están en un país en pleno desarrollo y que su mejor opción es cumplir los mínimos imperativos legales para no encontrarse dentro de una vorágine de normas que lo sancionan; en lugar de perder tiempo evadiendo las normas laborales, deben cumplirlas, puesto que así contribuirán realmente con el desarrollo del país (principal función de las inversiones nacionales e internacionales), creando a largo plazo tal vez un Estado desarrollado. Así mismo, una consecuencia lógica de reducir los índices de riesgo (principal función de los imperativos legales) en las labores de los trabajadores generará la disminución de siniestros y enfermedades profesionales.

Lo mencionado líneas arriba no busca la eliminación progresiva de la intervención estatal, sino de evitar una intervención obligada y apresurada del Estado; tampoco se debe pensar que al cumplirse, aparentemente, los de- 
rechos laborales ya no deben existir inspecciones; al contrario deben haber inspecciones investigativas, pero en menor medida, porque así las partes del mercado laboral actuarán con responsabilidad social. La consecuencia lógica de este accionar es la disminución de inspecciones investigativas, generando el incremento de inspecciones orientadoras (pedagógico-preventiva), las cuales serían de gran ayuda por la gran proliferación existente en la actualidad de normas en materia laboral a consecuencia, creemos, de la gran cantidad de regímenes laborales, por ello el gasto de recursos estatales estaría dirigido a orientar al empleador y a los trabajadores sobre las variaciones y modificaciones legislativas.

\section{CONCLUSIONES}

Los derechos sociales cobran mayor realce al erigirse el estado de bienestar a partir de sucesos determinantes, como las crisis financieras y las guerras mundiales; desde esa época se germinó el concepto de seguridad y salud en el trabajo.

La interrelación laboral puede graficarse como un mercado, el «mercado laboral», donde los actores principales son las empresas que contratan directa o indirectamente con los trabajadores y las empresas de seguros, las cuales _ como se mencionó_- pueden ser personas que coadyuven al cumplimiento de los derechos laborales, como los de la seguridad y salud en el trabajo, mediante políticas de incentivos.

Instituciones de inspección laboral, como la SUNAFIL, y las mismas normas sancionadoras del ordenamiento jurídico y las inspecciones investigativas son reacciones estatales inmediatas como consecuencia de la vulneración de derechos laborales; en este caso, los de seguridad y salud en el trabajo.

La suficiencia del mercado laboral permitirá ahorrar recursos patrimoniales y humanos en las inspecciones investigativas que buscan sancionar las infracciones, de ese modo se podrán redirigir esos recursos hacia las inspecciones orientadoras y así evitar la continua intervención reactiva del Estado. Esta lógica también puede aplicarse a los derechos sociolaborales constantemente vulnerados en nuestro territorio y quien sabe tal vez a todos los derechos tutelados por el ordenamiento.

La idea no es hacer un análisis económico de costo-beneficio sobre si es mejor pagar las multas o cumplir con los derechos laborales, sino informar a las empresas del mercado laboral que su ineficiencia en el mercado ocasiona una intervención del Estado obligada por las circunstancias y que dicha fiscalización la realizará un estado del tercer mundo, con todas las 
implicancias que esa connotación trae consigo, por ejemplo la dación muy apresurada de leyes con aumento de sanciones o normas excesivamente generales sin criterios específicos para los servidores (inspectores de trabajo), quienes procurarán en base a esa norma el cumplimiento de derechos laborales por parte de los empleadores.

\section{DATO ADICIONAL}

La Ley General de Inspección de Trabajo es casi una copia literal del Convenio 81 de la Organización Internacional Trabajo, pero una de las diferencias que salta a la vista es que para el Convenio 81 los inspectores de trabajo deben ser funcionarios públicos, hecho que no se configura en la ley porque los inspectores de trabajo son servidores públicos. 